Penelitian

\title{
Perilaku Memelihara Burung Paruh Bengkok di Maluku Utara
}

\author{
(Parrot Bird-keeping in North Maluku) \\ Irfan Rosyadi*, Bambang Tetuka, Eben Embeua, Erfa Mukaram, Nyong Barakai, Ronal Djorebe
}

Burung Indonesia, J. Dadali No. 32, Bogor 16161, Indonesia. *Penulis untuk korespondensi: hcyanoventris@gmail.com Diterima 7 Januari 2015, Disetujui 30 April 2015

\begin{abstract}
ABSTRAK
Kajian tentang pemeliharaan burung paruh bengkok di Maluku Utara telah dilaksanakan pada bulan April sampai bulan Juli 2012. Metode pengumpulan data yang digunakan adalah survei dengan melakukan wawancara terhadap 800 responden rumah tangga di 2 kota di Maluku Utara, yaitu Ternate dan Tobelo. Sebanyak 28 pertanyaan diajukan kepada responden terkait kepemilikan burung, cara mendapatkan, cara pemeliharaan, alasan memelihara, serta persepsi terhadap perilaku memelihara burung terkait dengan kelestariannya. Hasil penelitian menunjukkan sebanyak 13,6\% rumah tangga memelihara burung. Jenis yang paling banyak dipelihara adalah burung paruh bengkok, seperti kasturi ternate Lorius garrulus (68,2\%), kemudian disusul secara berurut-urut kakatua putih Cacatua alba $(10,1 \%)$, nuri bayan Eclectus roratus (7,3\%) dan nuri kalung-ungu Eos squamata (16\%), sementara jenis lainnya adalah nuri kepala hitam Lorius lory, serta bukan jenis paruh bengkok seperti julang irian Rhyticeros plicatus, merpati Columba livia, dan pergam kaca mata Ducula perspicillata dengan jumlah kira-kira sama. Alasan memelihara burung paling banyak adalah karena bisa menirukan kata $(75,3 \%)$. Burung biasanya dipelihara dengan merantai kakinya di gantungan kayu (71\%) dan pemelihara juga mencabut bulu sayap burung untuk mencegahnya terbang (34\%). Rendahnya pengetahuan terhadap pemeliharaan burung berdampak pada tidak terpenuhinya kesejahteraan burung peliharaan dan rendahnya kesadaran terhadap kelestarian burung menjadi ancaman utama kepunahan burung di alam.
\end{abstract}

Kata kunci: paruh bengkok, perilaku memelihara burung, Maluku Utara, wawancara

\begin{abstract}
Information of parrots bird keeping in North Maluku is available since the study has been conducted during April until July 2012. We interviewed 800 households in Ternate and Tobelo, North Maluku with total of 28 questions. The Questions were about the ownership of the birds, how to get, reason and how to keep care, as well as the perception of bird conservation related to bird-keeping. The results showed $13.6 \%$ of households keeping birds. Chattering lory Lorius garrulus were found to be the most popular pet (68.2\%), followed by white cockatoo Cacatua alba (10.1\%), eclectus parrot Eclectus roratus (7.3\%) and violet-necked lory Eos squamata ( $16 \%$ ), the rest is divided equally respectively black-capped lory Lorius lory, and non-parrot species; blyth's hornbill Rhyticeros plicatus, rock dove Columba livia, spectacled imperial-pigeon Ducula perspicillata. Birds were usually found with chained legs on wooden hangers (71\%) and about 34\% bird found with the flight feather hacked off to prevent escape. The concern for animal welfare were relatively low as well as for bird conservation.
\end{abstract}

Key words: Parrot, bird-keeping, Ternate, Tobelo North Maluku, interview 


\section{PENDAHULUAN}

Burung paruh bengkok adalah salah satu jenis burung peliharaan paling popular di dunia. Hal ini memberikan dampak buruk terhadap kelestarian burung paruh bengkok. Dari 356 spesies burung paruh bengkok, sebanyak 123 jenis telah mendekati terancam punah atau lebih parah dan 16 jenis telah berstatus critically endangered (Birdlife International, 2014).

Pemeliharaan jenis burung paruh bengkok di Indonesia sendiri sebenarnya masih tergolong kecil dengan jenis burung kicauan, khususnya di Sumatera. Di lima kota Besar di Indonesia (Jakarta, Semarang, Surabaya, Bandung dan Medan) menunjukkan 21,8\% kepala keluarga memelihara burung sebagai hewan kesayangan. Burung yang paling umum dipelihara adalah burung domestik, jenis burung berkicau tangkaran, burung berkicau tangkapan, burung impor dan juga burung paruh bengkok (Jepson \& Ladle, 2005). Jenis burung paruh bengkok yang dipelihara di kota-kota besar di Indonesia umumnya berasal dari wilayah timur, seperti Maluku dan Papua (Amama, 2006).

Maluku Utara memiliki 9 jenis burung paruh bengkok dan empat jenis diantaranya sering di- tangkap dan diperdagangkan. Burung paruh bengkok dari daerah ini telah banyak dikenal dan dipelihara oleh pecinta burung di dunia. Sebagai salah satu daerah asal burung paruh bengkok, masyarakat di Maluku Utara juga memiliki kebiasaan memilihara burung (Bashari \& Nurdin, 2009).

Tulisan ini membahas tentang pemeliharaan burung paruh bengkok di 2 kota paling padat di Maluku Utara yaitu Ternate dan Tobelo. Pembahasan difokuskan pada dan jenis apa saja yang dipelihara oleh masyarakat di Maluku Utara, motivasi masyarakat memelihara burung, serta mengetahui bagaimana tata cara memelihara burung oleh masyarakat.

\section{BAHAN DAN METODE}

Survei dilaksanakan pada bulan April sampai Juli 2012 di dua kota terbesar di Maluku Utara, yaitu Ternate dan Tobelo. Pengambilan data di Ternate dilakukan tanggal 9 sampai 25 April 2012, sedangkan di Tobelo dilaksanakan tanggal 11 sampai 17 Juli 2012. Pengambilan data kuesioner dilaksanakan di 32 Desa/Kelurahan yang tersebar di 10 Kecamatan (Tabel 1 dan Gambar 1).

Tabel 1 Lokasi pengambilan data kuesioner

\begin{tabular}{|c|c|c|c|}
\hline \multicolumn{2}{|c|}{ Tobelo } & \multicolumn{2}{|c|}{ Ternate } \\
\hline Kecamatan & Desa & Kecamatan & Desa \\
\hline Tobelo Utara & Gurua & Ternate Selatan & Mangga dua \\
\hline Tobelo Utara & Ruko & Ternate Selatan & Gambesi \\
\hline Tobelo Utara & Popilo & Ternate Selatan & Bastiong \\
\hline Tobelo Tengah & WKO & Ternate Selatan & Jati \\
\hline Tobelo Tengah & Wosia & Ternate Tengah & Tanah raja \\
\hline Tobelo Tengah & Pitu & Ternate Tengah & Santiong \\
\hline Tobelo Timur & Mawea & Ternate Tengah & Kota Baru \\
\hline Tobelo Timur & Katana & Ternate Tengah & Marikarubu \\
\hline Tobelo Selatan & Kakara & Ternate Utara & Sangaji \\
\hline Tobelo Selatan & Kupa-Kupa & Ternate Utara & Akehuda \\
\hline Tobelo Selatan & Tomahalu & Ternate Utara & Tafure \\
\hline Tobelo Barat & Kusuri & Ternate Utara & Tubo \\
\hline Tobelo & Tagalaya & Ternate Selatan & Sulamadaha \\
\hline Tobelo & Gamsungi & Ternate Selatan & Takome \\
\hline Tobelo & Gura & Ternate Selatan & Kastela \\
\hline Tobelo & Gos oma & Ternate Selatan & Foramadiahi \\
\hline
\end{tabular}




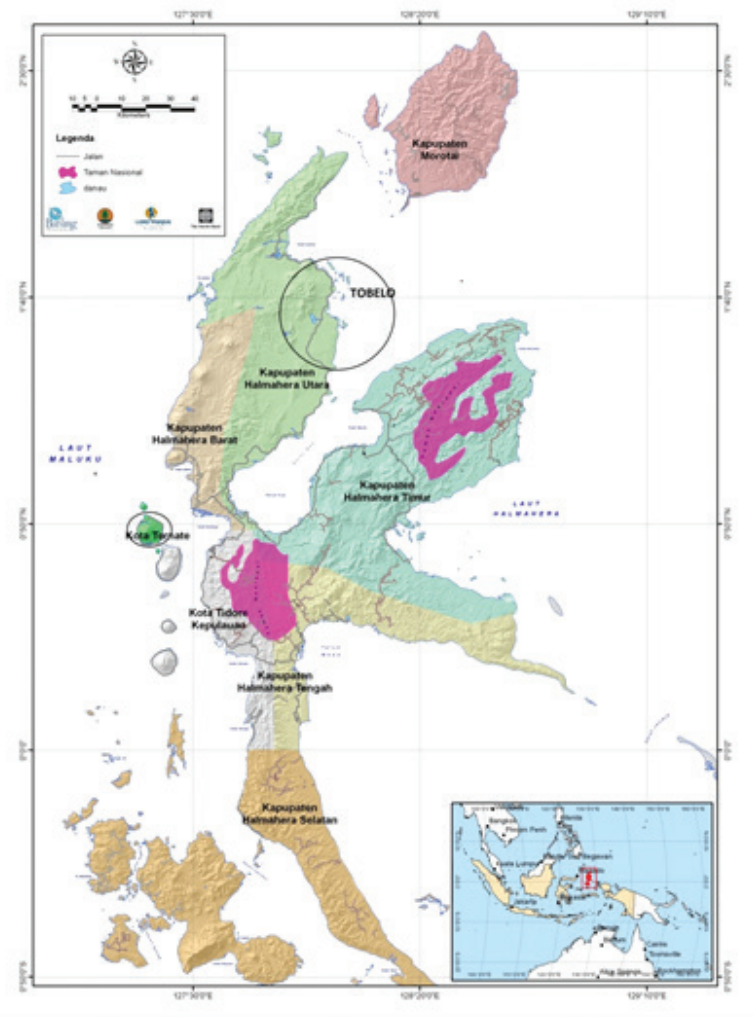

Gambar 1 Peta lokasi pengambilan data di Ternate dan Tobelo

Metode yang digunakan adalah dengan wawancara menggunakan Kuesioner. Dari 32 Desa/kelurahan diambil masing-masing 25 responden rumah tangga (total 800 responden). Pengambilan cuplikan rumah tangga dilakukan secara acak tanpa memperhitungkan kepemilikan burung. Wawancara berisi 28 pertanyaan yang ditujukan kepada perwakilan rumah tangga. Pertanyaan yang diajukan kepada responden diantaranya meliputi: kepemilikan burung, cara mendapatkan, cara pemeliharaan, alasan memelihara, lama pemeliharaan burung, alasan berhenti memelihara burung serta persepsi terhadap perilaku memelihara burung terkait dengan kelestariannya. Jawaban ditulis sesuai dengan jawaban responden. Data yang diambil kemudian dianalisis menggunakan program Survey Pro 2.0 (Apian Software Inc, 1995).

\section{HASIL}

Hasil penelitian menunjukkan sebanyak 13,6\% (109 responden) memelihara burung. Hasil ini memperlihatkan bahwa cukup mudah untuk menemukan pemelihara burung di Ternate dan Tobelo. Secara rata-rata, maka dari setiap sepuluh rumah tangga minimal satu diantaranya memelihara burung. Persebaran pemelihara burung tidak merata di tiap desa atau kelurahan. Ada kelurahan yang sangat banyak pemelihara burungnya, tetapi ada juga yang jarang atau sangat jarang.

Pada responden yang tidak memelihara burung, diketahui bahwa 29,8\% dari mereka mempunyai niat dan berminat memelihara burung di waktu mendatang. Tetapi, dalam kuesioner tidak dijelaskan alasan mengapa mereka tidak memelihara burung. Sebagian besar diketahui memiliki riwayat pernah memelihara burung sebelumnya.

Dari 109 pemelihara burung, paling sering burung diperoleh dari pemberian (Ternate $48,7 \%$ dan Tobelo 32,7\%), dari membeli (Ternate 33,3\% dan Tobelo 31,8\%), serta dari menangkap di alam (Ternate 14,5\% dan Tobelo 29,1\%) (Gambar 2).

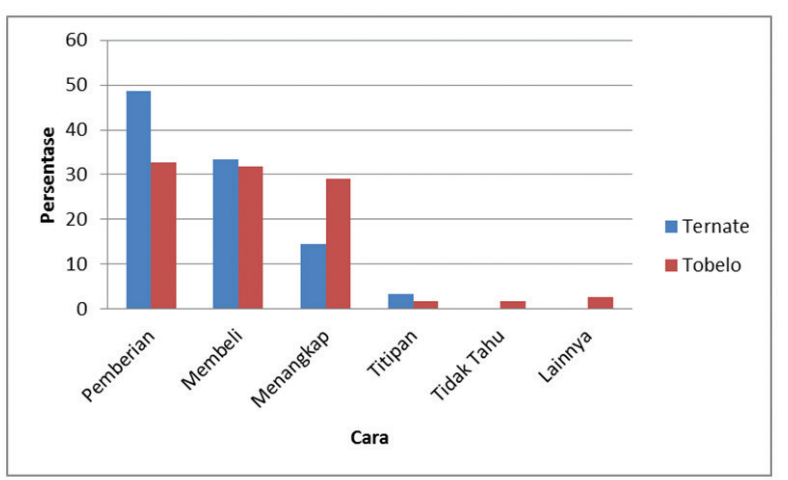

Gambar 2 Persentase cara mendapatkan burung peliharaan di Ternate dan Tobelo

Terdapat 4 jenis burung yang paling banyak dipelihara oleh warga di Tobelo dan Ternate, yaitu kasturi ternate (Lorius garrulus) sebanyak 68,2\%, kakatua putih (Cacatua alba) 10,1\%, dan nuri kalungungu (Eos squamata) 16\%) nuri bayan (Eclectus roratus) $7,3 \%$. Sementara jenis lainnya adalah nuri kepala-hitam (Lorius lorry), julang irian (Rhyticeros plicatus), merpati (Columba livia), dan pergam/ pombo (Ducula perspicillata) dengan jumlah kirakira sama (Gambar 3).

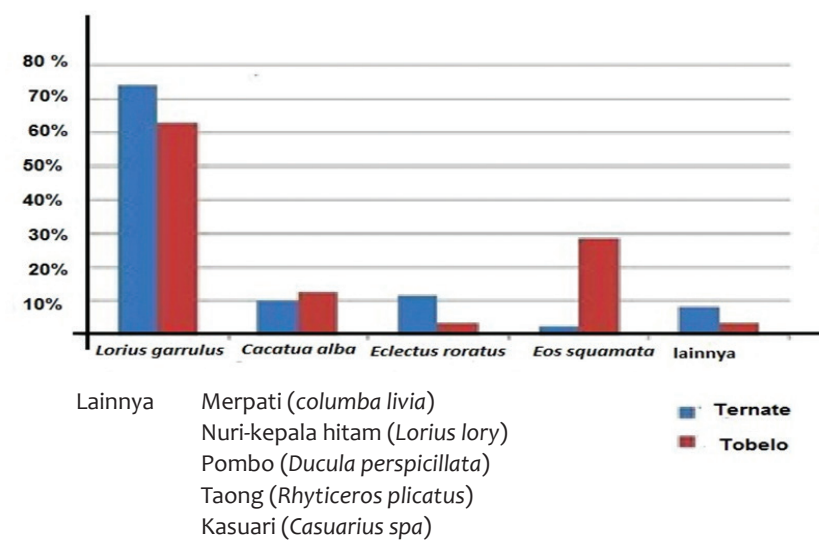

Gambar 3 Jenis burung yang dipelihara di Ternate dan Tobelo 


\section{4 | Rosyadi et al.}

Alasan paling umum memelihara burung adalah karena suka dengan burung (di Tobelo 42 pemelihara, Ternate 34 pemelihara), alasan yang lain cukup beragam diantaranya untuk hiburan, hiasan rumah, dan ada juga yang menjawab untuk persiapan kenang-kenangan saat sekolah atau kerja. Di Tobelo ada yang memelihara burung untuk tujuan bisnis dan ada juga yang digunakan sebagai umpan untuk menangkap burung (Gambar 4). Sementara untuk pemilihan jenis burung, umumnya adalah karena burungnya pintar atau bisa dilatih menirukan kata (75,3\%), burung yang dimaksud biasanya adalah jenis kasturi ternate (Gambar 5).

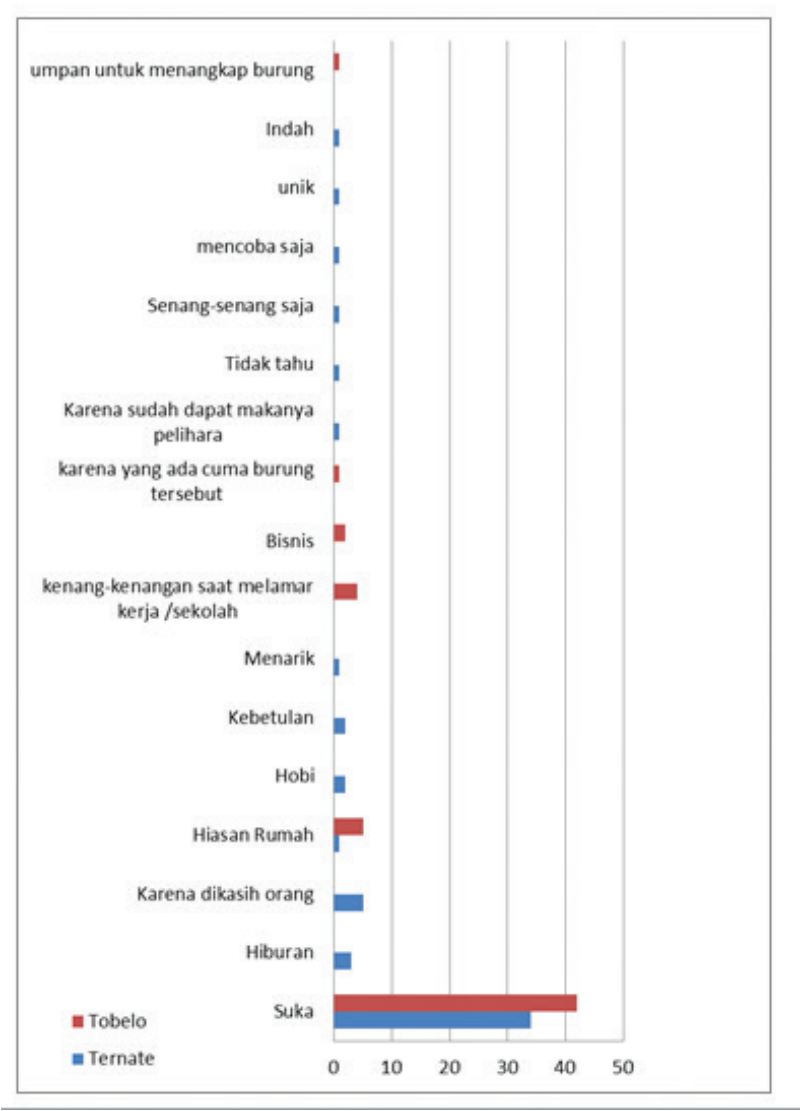

Gambar 4 Alasan memelihara burung di Ternate dan di Tobelo

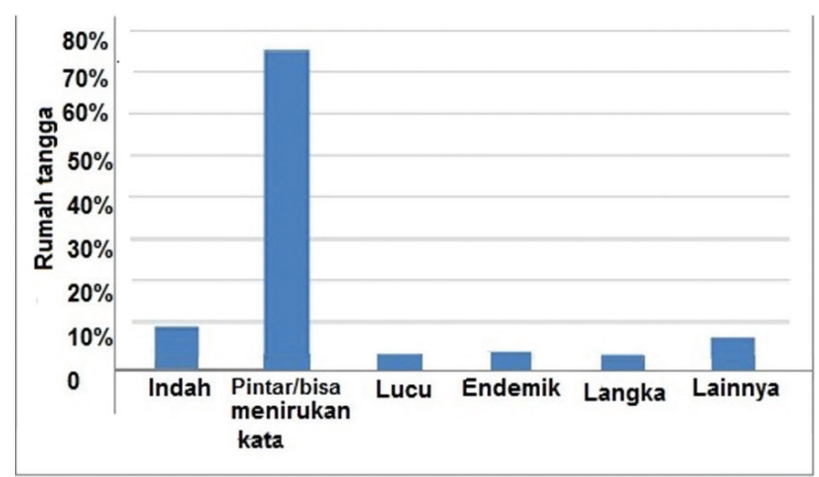

Gambar 5 Alasan pemilihan jenis burung peliharaan di Ternate dan Tobelo
Data dari kuesioner menunjukkan bahwa cara responden memelihara burung peliharaannya paling banyak (71\%) adalah dengan mengikat kakinya menggunakan rantai di gantungan (Gambar 6). Gantungan biasanya berupa kayu atau bambu yang dibuat setengah lingkaran atau segitiga. Bagian bawah berbentuk datar sebagai tempat bertengger dengan panjang sekitar 25-30 cm. Bagian atasnya berupa setengah lingkaran biasanya terbuat dari kayu atau potongan bambu lentur. Dengan cara pemeliharaan seperti ini burung tidak bisa bergerak bebas, terkadang burung terjatuh dan menggantung dengan satu kaki dirantai. Hal ini pula yang dilakukan para penangkap burung ketika memelihara di rumah atau menjualnya ke pembeli. Cara seperti ini sudah menjadi hal yang lazim dilakukan dalam memelihara burung paruh bengkok di Maluku Utara. Sebagian yang lain memelihara burung di dalam sangkar yang berukuran sangat sempit, yaitu ukuran sisinya kurang dari $50 \mathrm{~cm}$. Sempitnya kandang tidak memberi ruang bagi burung untuk sekedar terbang berpindah. Kandang yang digunakan umumnya terbuat dari kawat, yang dapat menyebabkan bulu-bulu ekor rusak akibat tergores kawat dinding kandang.

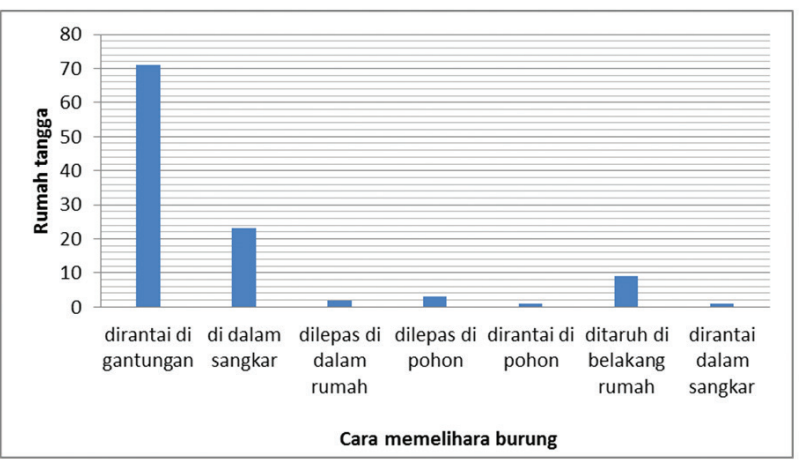

Gambar 6 Metode pemeliharaan burung di Ternate dan Tobelo.

Burung paruh bengkok juga ada yang dipelihara dengan melepas di pohon depan rumah. Biasanya pada sore hari burung akan dimasukkan dalam kandang. Cara seperti ini hanya bisa dilakukan pada burung yang sudah jinak, selain itu bulu primernya sudah dicabut atau dipotong agar tidak bisa terbang. Hasil survei memperlihatkan bahwa 34\% pemelihara mencabut atau memotong bulu sayap primer pada burung piaraannya. 


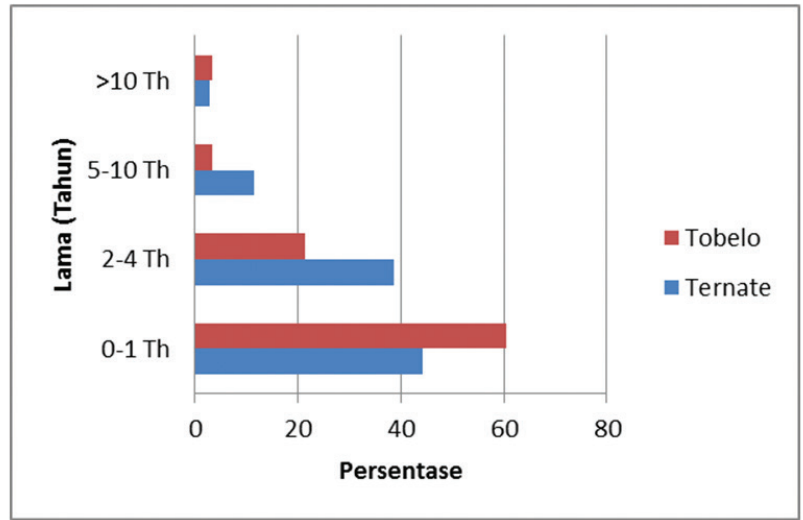

Gambar 7 Jangka waktu pemeliharaan burung oleh masyarakat di Ternate dan Tobelo.

Berdasarkan data kuesioner yang diperoleh dari responden yang pernah memelihara burung, memperlihatkan kecenderungan adanya korelasi negatif antara lama pemeliharaan dengan jumlah pemelihara. Gambar 7 memperlihatkan semakin lama pemeliharaan, semakin sedikit pemelihara yang bisa melakukannya. Lama pemeliharaan pada umumnya berkisar 0-1 tahun, di Ternate yaitu sebanyak 44,3\% sedangkan di Tobelo 60\%. Alasan berhenti memelihara burung paling banyak karena burungnya mati, yaitu di Ternate sebanyak 52\% dan Tobelo 32,9\% (Gambar 8).

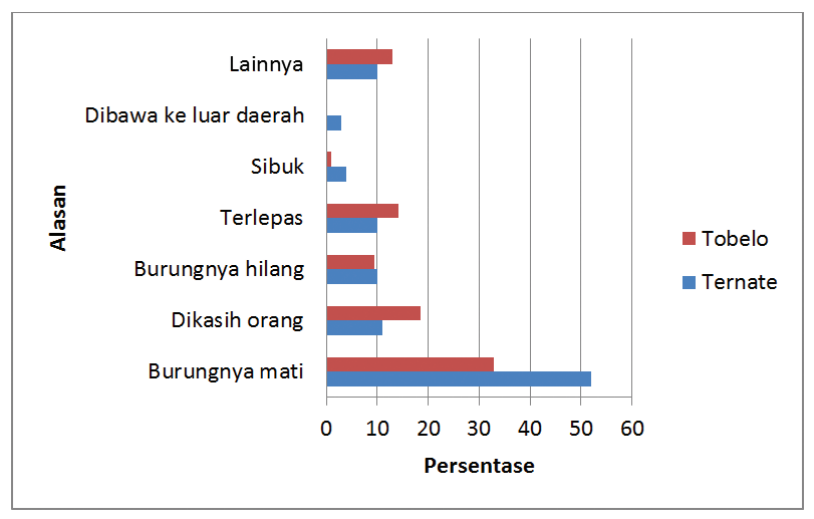

Gambar 8 Alasan masyarakat di Ternate dan Tobelo berhenti memelihara burung

Terkait kelestarian burung-burung yang dipelihara sebagian besar responden pemelihara mengatakan tidak khawatir bahwa memelihara burung dapat menyebabkan kepunahan populasi burung di alam. Sebanyak 34,07\% beralasan karena burung masih banyak, 19,9\% mengatakan karena mereka hanya memelihara dalam jumlah yang sedikit. Sementara $34,56 \%$ responden menyatakan khawatir tetapi tidak ingin memelihara burung, hanya $11,45 \%$ responden yang memang menyatakan khawatir (Gambar 9).
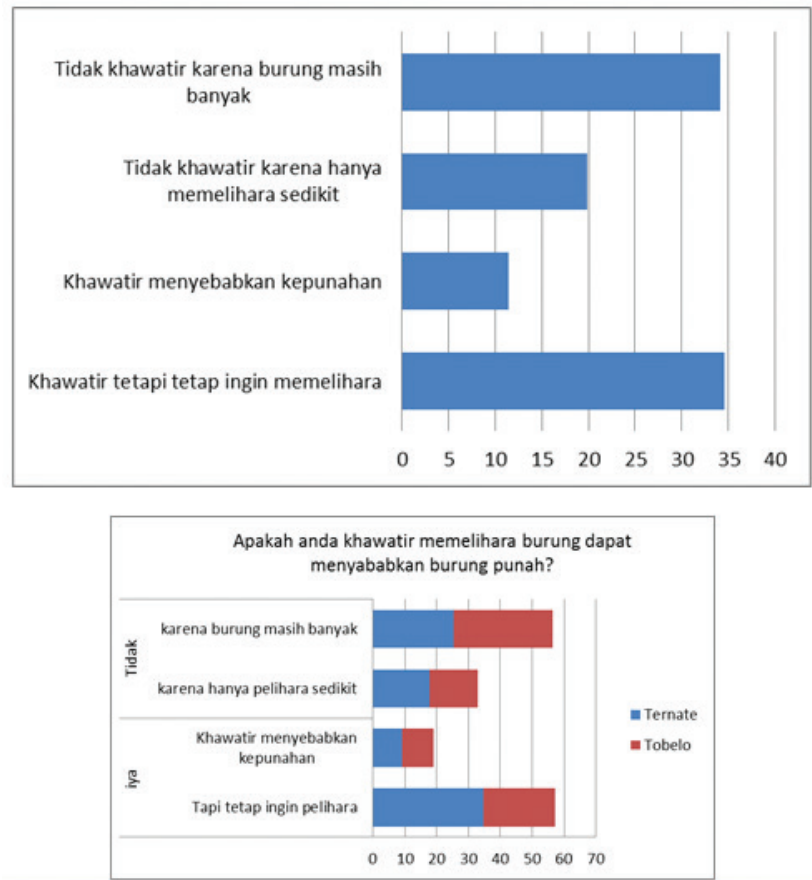

Gambar 9 Tingkat kesadaran masyarakat tentang pengaruh memelihara burung di rumah dengan kepunahan burung

\section{PEMBAHASAN}

Berdasarkan hasil penelitian ini, diketahui bahwa jenis-jenis burung yang dipelihara oleh responden hampir semuanya berasal dari wilayah Maluku Utara (Gambar 10) yang relatif mudah ditemui di hutan dan di dekat tempat tinggal mereka. Jenis burung yang dipelihara adalah burung paruh bengkok yang cukup dikenal di dunia maupun oleh masyarakat lokal sebagai burung khas Maluku. Hanya ada jenis burung peliharaan dari luar yang ditemukan yaitu nuri kepala-hitam (Lorius lorry) dan kasuari yang berasal dari Papua. Hal ini sangat berbeda dengan pemelihara burung di Jawa yang umumnya memelihara burung kicauan, dengan jenis yang beragam (Amama, 2006). Pemelihara burung di Maluku Utara tidak banyak mengenal jenis burung piaraan lain yang berasal dari luar Maluku Utara, bahkan yang sangat terkenal seperti parkit, love bird dan kenari. Jenis dari luar yang sangat mereka kenal hanya burung dara (Columba livia) dengan jumlah pemeliharanya hanya $2,15 \%$ dari seluruh rumah tangga. Kebiasaan memelihara burung di Maluku Utara tergolong masih baru jika dibandingkan dengan di Jawa yang sudah menjadi budaya turun-temurun. 

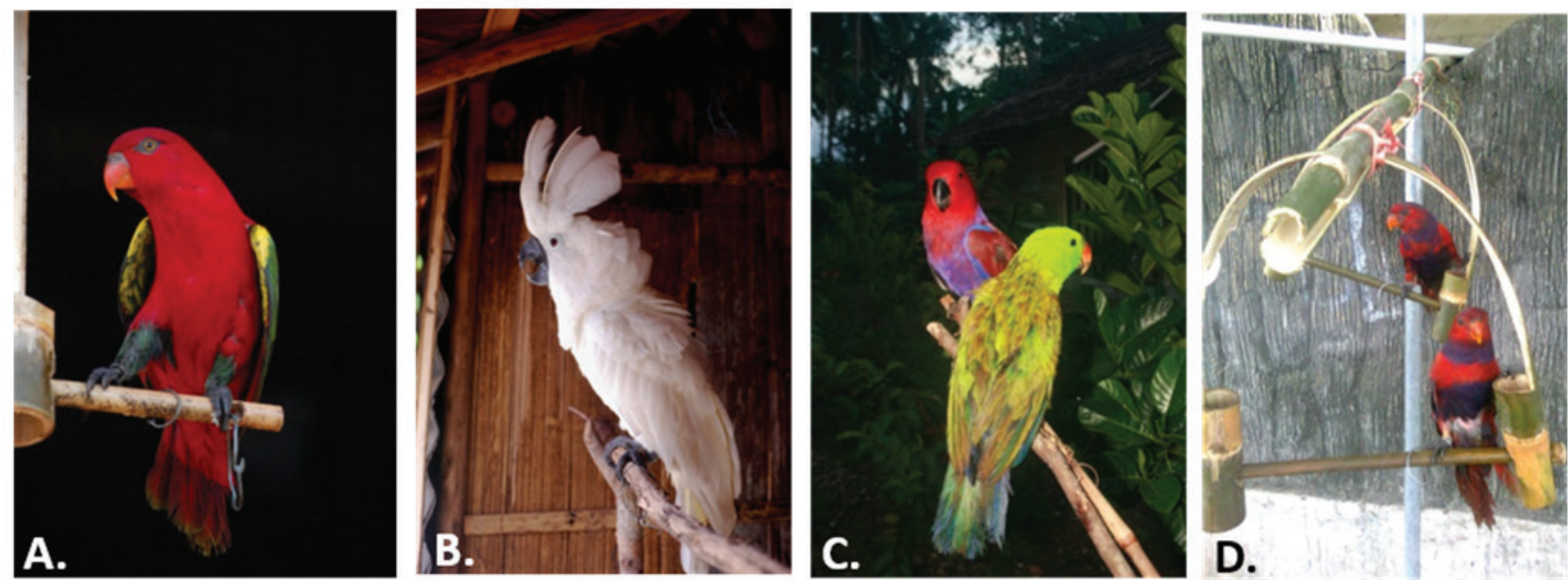

Gambar 10 A. kasturi ternate, Lorius garrulus, B. Kakatua putih, Cacatua alba, C. Nuri bayan Eclectus roratus, D. Nuri kalungungu, Eos squamata.

Dalam jalur perdagangan burung, Maluku Utara merupakan daerah hulu (produsen) burung paruh bengkok (Lambert, 1993). Pemelihara lokal bisa mendapatkan burung lebih mudah dan murah. Harga dari penangkap untuk Kakatua putih Rp. 150,000300,000, kasturi ternate antara Rp. 50,000-150,000, nuri bayan Rp. 75,000-150,000 dan nuri kalung-ungu Rp. 30,000-50,000 (Bashari \& Nurdin, 2009).

Hasil penelitian juga memperlihatkan banyak pemelihara burung yang mendapatkan burung dari pemberian (Ternate $48,7 \%$ dan di Tobelo $32,7 \%$ ). Hal ini dikarenakan burung paruh bengkok merupakan burung khas yang sering dijadikan cenderamata ketika datang ke tempat saudara, atasan atau mitra kerja untuk mempererat hubungan. Pemberian burung menjadi hal yang tidak memberatkan karena harga burung yang masih relatif murah. Selain pemberian mereka juga bisa menangkap sendiri (Tobelo $29 \%$, Ternate $14,5 \%$ ). Beberapa responden di desa yang di wawancara merupakan penangkap burung yang tinggal dekat dengan hutan. Di Ternate juga ditemukan empat kasus responden yang langsung menangkap di alam. Keberadaan kakatua putih di Ternate tinggal sedikit, tapi sering datang di kebun masyarakat sehingga mudah untuk ditangkap. Sedang untuk burung kasturi ternate menurut data yang diperoleh hasil pemberian dan pembelian, tidak ada pemelihara burung yang mendapat burung kasturi ternate dari menangkap di alam.

Hasil wawancara terhadap responden yang pernah menjadi pemelihara burung, menunjukkan bahwa mereka berhenti memelihara karena burungnya mati. Kematian burung paling sering terjadi pada sekitar o sampai 1 tahun pemeliharaan. Padahal burung paruh bengkok jenis kasturi ternate bisa hidup hingga 20 tahun dan kakatua putih bisa mencapai 40 tahun (Arndt, 1995; Alderton, 1992). Kematian yang tinggi ini karena pemelihara tidak cukup memiliki pengetahuan dan keterampilan tentang cara merawat burung dengan benar. Kebanyakan burung dirantai di kayu penggantung yang hanya memberi sedikit ruang gerak. Selain itu bulu-bulu sayap primer sering dipotong atau dicabut supaya tidak bisa terbang. Jenis pakan sangat terbatas pada buah pisang dan kadang-kadang diberi roti. Jenis kasturi ternate terkadang diberi tebu atau air gula.

Selain itu hasil penelitian juga menunjukkan masih banyak masyarakat yang kurang sadar bahwa memelihara burung di kandang bisa menyebabkan kepunahan. Hal ini disebabkan karena mereka beranggapan bahwa populasi burung di hutan masih banyak. Hanya sedikit dari pemelihara burung yang khawatir perilaku mereka tersebut menyebabkan kepunahan, namun tetap ingin memelihara burung. Data penelitian ini memperlihatkan selain kepedulian, juga pemahaman masyarakat tentang kelestarian burung di alam masih rendah. Birdlife International (2003) menyebutkan bahwa 35 jenis burung di Asia telah terancam punah (Critically endangered dan 25 jenis Endangered) akibat penangkapan untuk peliharaan.

Dari data tersebut di atas dapat disimpulkan bahwa pemelihara burung di Ternate dan Tobelo didominasi jenis burung paruh bengkok yaitu kasturi ternate, kakatua putih nuri bayan dan nuri kalungungu. Kasturi ternate merupakan jenis yang paling sering dipelihara masyarakat, karena memiliki warna yang indah dan bisa dilatih menirukan suara manusia. Perhatian terhadap kesejahteraan burung peliharaan masih sangat rendah dengan tingkat kematian yang cukup tinggi. Masyarakat juga belum 
memahami akibat pemeliharaan burung terhadap kelestarian burung paruh bengkok di alam. Maraknya pemeliharaan burung paruh bengkok ini menunjukkan bahwa peredaran burung di tingkat lokal cukup tinggi.

\section{UCAPAN TERIMA KASIH}

Kajian ini merupakan bagian dari proyek Burung Indonesia yang didanai oleh Loroparque Fundation, dan ZGAP. Terimakasih disampaikan kepada temanteman kantor lapangan di Halmahera, Enumerator serta Mahasiswa Universitas Halmahera:, Indriyati A Yusuf Kamal, Sofiana T. Bie, Nurfita Lasae, Stevi Christina Liotohe, Jems Tjuana, Jackson Mamulaty. Hanom Bashari, Dwi Mulyawati, Fahrul P. Amama atas masukan selama merancang kuesioner, Hilda Lionata dan Andriansyah atas kritik dan masukan selama penyusun paper ini.

"Penulis menyatakan tidak ada konflik kepentingan dengan pihak-pihak yang terkait dalam penelitian ini"

\section{DAFTAR PUSTAKA}

Alderton D. 1992. You \& Your Pet Bird. Alfred A. Knopf, Inc. New York. p116.

Amama FP. 2006. Survei Sosial, Perubahan Sosial dan Konservasi. Laporan Teknis Burung Indonesia, Bogor, Indonesia. p1-4.

Apian S. 1995. Survey Pro. 2.0 User Guide: Tutorial How to and Reference. Apian Software, Inc Seattle. p2-10.
Arndt T. 1995. Lexicon of parrots. Arndt Verlag, Bretten, Germany. 4: 67.

Bashari, Nurdin. 2009. Burung Paruh bengkok dan status perburuan serta perdagangannya di Maluku Utara, laporan teknis. Burung Indonesia Bogor. Indonesia. p 6,7,22,23.

Bird Life International. 2001. Threatened Bird of Asia: The BirdLife International Red Data Book. BirdLife International, Cambridge, UK. p16691673.

BirdLife International. 2003. Saving Asia's Threatened Birds. A Guide for Government and Civil Society. BirdLife International, Cambridge, UK. p38.

Bird Life International. 2013. Cacatua alba. The IUCN Red List of Threatened Species. Version 2014.3. www.iucnredlist.org

Coates BJ, Bishop KD, Gardner D. 1997. A Guide To The Birds of Wallacea, Sulawesi, The Moluccas and Lesser Sundas Island, Indonesia. Dove Publication Pty. Ltd. Queensland. p330-343.

Lambert FR. 1993 .The status of and trade North Mollucan Parrots, With particular emphasis on Cacatua alba, Lorius Garrulus and Eos squamata, IUCN-The Nature Conservation Union/SSC Trade Specialist group. IUCN, Gland, Switzerland and Cambridge, UK. p64.

Jepson P, Ladle R J. 2005. Bird-keeping in Indonesia: conservation impacts and the potential for substitution-based conservation responses. Journal Oryx 39: 442-448. 